\title{
Oxidation kinetics of reaction-sintered silicon carbide
}

\author{
O P CHAKRABARTI and J MUKERJI \\ Central Glass and Ceramic Research Institute, Jadavpur, Calcutta 700032, India
}

MS received 2 December 1991; revised 28 December 1992

\begin{abstract}
The oxidation kinetics of reaction-sintered silicon carbide has been studied over the temperature range $1200^{\circ}$ to $1350 \mathrm{C}$. The material has a bulk density of $3.00 \mathrm{~g} / \mathrm{cm}^{3}$ and the unreacted $S_{1}$ content is $22.5^{\circ}{ }^{\circ}(\mathrm{v} / \mathrm{v})$. The activation energy for oxidation is $28.75 \pm$ $2.61 \mathrm{kcal} / \mathrm{mol}$. It is proposed that the diffusion of oxygen through the growing oxide film is the rate-controlling process.
\end{abstract}

Keywords. Oxidation; silicon carbide.

\section{Introduction}

Silicon carbide is an important non-oxide ceramic material which has found increased interest for high-temperature structural applications because of its excellent hightemperature strength and high resistance to oxidation. There are many publications on the oxidation behaviour of various types of silicon carbide. Most of the early studies (Ervin 1958; Jorgensen et al 1959; Adamsky 1959; Pultz 1967; Kurycheva and Bresker 1969) used powdered silicon carbide. Hinze et al (1975) and Singhal (1976) used commercially available hot-pressed material and studied oxidation in oxygen atmosphere. Costello and Tressler (1981) studied the oxidation kinetics of sintered and hot-pressed silicon carbide in air. Schiroky (1987) reported the oxidation behaviour of chemically vapour-deposited silicon carbide. However, oxidation of reaction-sintered silicon carbide has been the subject of very few investigations. Recently, Gogotsi et al (1989) reported the oxidation of reaction-sintered silicon carbide. In this paper, oxidation of reaction-sintered silicon carbide in the temperature range $1200-1350^{\circ} \mathrm{C}$ in air has been reported.

\section{Experimental}

\subsection{Material}

Reaction-sintered silicon carbide (RSSC) was prepared in our laboratory from commercial $\alpha$-SiC powder of 400-mesh grit size. The powdered material contains $98.20 \mathrm{wt} \% \mathrm{SiC}, 0.25 \mathrm{wt} \%$ free C, $0.4 \mathrm{wt} \%$ free $\mathrm{Si}, 0.5 \mathrm{wt} \% \mathrm{SiO}_{2}$ and $0.04 \mathrm{wt} \% \mathrm{Fe}_{2} \mathrm{O}_{3}$. The material to be studied has a bulk density of $3.00 \mathrm{~g} / \mathrm{cm}^{3}$. Unreacted Si content, as measured by XRD as well as from density calculation, was found to be $22.5 \%$. SEM (figure 1) reveals that the duplex material consists of original $\alpha$-SiC, reaction-formed $\beta-\mathrm{SiC}$, and an almost continuous matrix of unreacted $\mathrm{Si}$. 


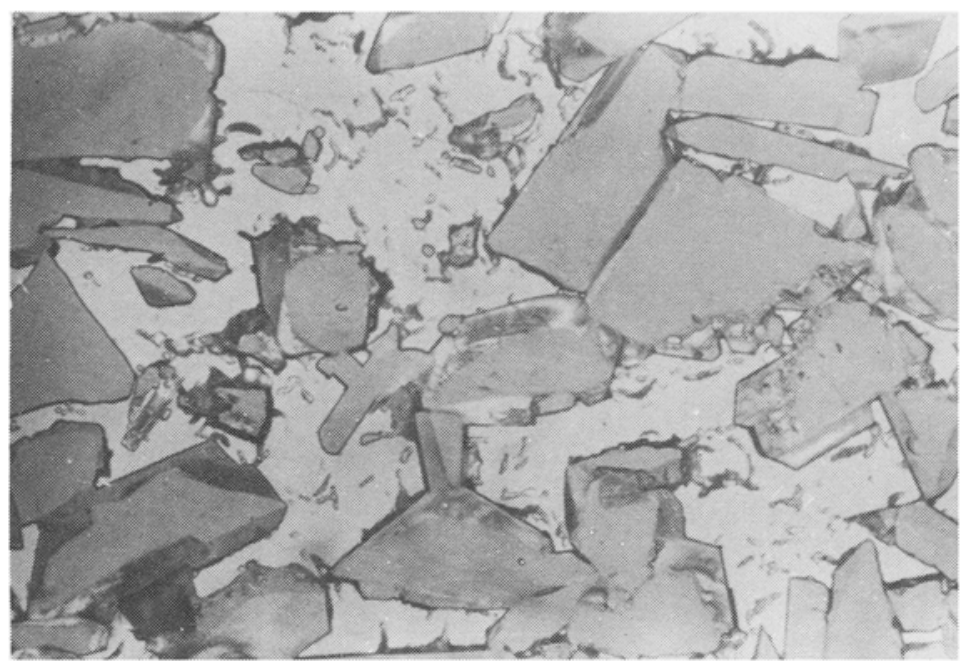

Figure 1. Optical micrograph of reaction sintered silicon carbide $(\times 450)$.

\subsection{Experimental procedure}

An electronic continuously recording microbalance capable of working under vacuum or under a controlled atmosphere and reading up to $0.01 \mathrm{mg}$ and a platinum wound furnace wherein the temperature could be controlled within $\pm 1^{\circ} \mathrm{C}$ with the help of a saturable core reactor-type controller were used. Oxidation runs were made by binding sample chips with a platinum wire, avoiding direct contact between the sample and the platinum wire by passing the wire through several small $\mathrm{Al}_{2} \mathrm{O}_{3}$ sheath pieces. The entire binding assembly weighed $1.7552 \mathrm{~g}$. The samples were taken in the form of chips of dimensions $20 \mathrm{~mm} \times 15 \mathrm{~mm} \times 1 \mathrm{~mm}$ cut from the RSSC billets. The samples were polished up to $1 \mu \mathrm{m}$ diamond paste finish. The polished and cleaned specimen was suspended from one end of the electrobalance and held inside an $\mathrm{Al}_{2} \mathrm{O}_{3}$ reaction tube at the desired temperature $\left(1200-1350^{\circ} \mathrm{C}\right)$. Changes in the weight of the specimen were continuously recorded on a strip chart recorder.

\section{Results and discussion}

The weight gain recorded was converted to weight gain per unit area and plotted against time (figure 2). All the curves show similar trends. After initial oxidation the weight-gain curves flatten out, showing protective action of the oxide layer formed. The maximum weight gain is $0.2530 \mathrm{mg} / \mathrm{cm}^{2}$ at $1300^{\circ} \mathrm{C}$ after $15 \mathrm{~h}$. The weight-gain data for the entire temperature range are found to fit best a parabolic reaction rate curve of the type $w^{2}=k t$, where $w$ is the weight gain per unit area, $k$ the constant, and $t$ time. A plot of $w$ against corresponding $\sqrt{t}$ is shown in figure 3 . The plot is a straight line for a given temperature and the slope of the straight line gives the value of $k$. The activation energy for oxidation is calculated from the Arrhenius equation $k=A \mathrm{e}^{-E / R T}$, where $A$ is the pre-exponential factor independent of temperature, $E$ the activation energy, and $R$ and $T$ the gas constant and absolute 


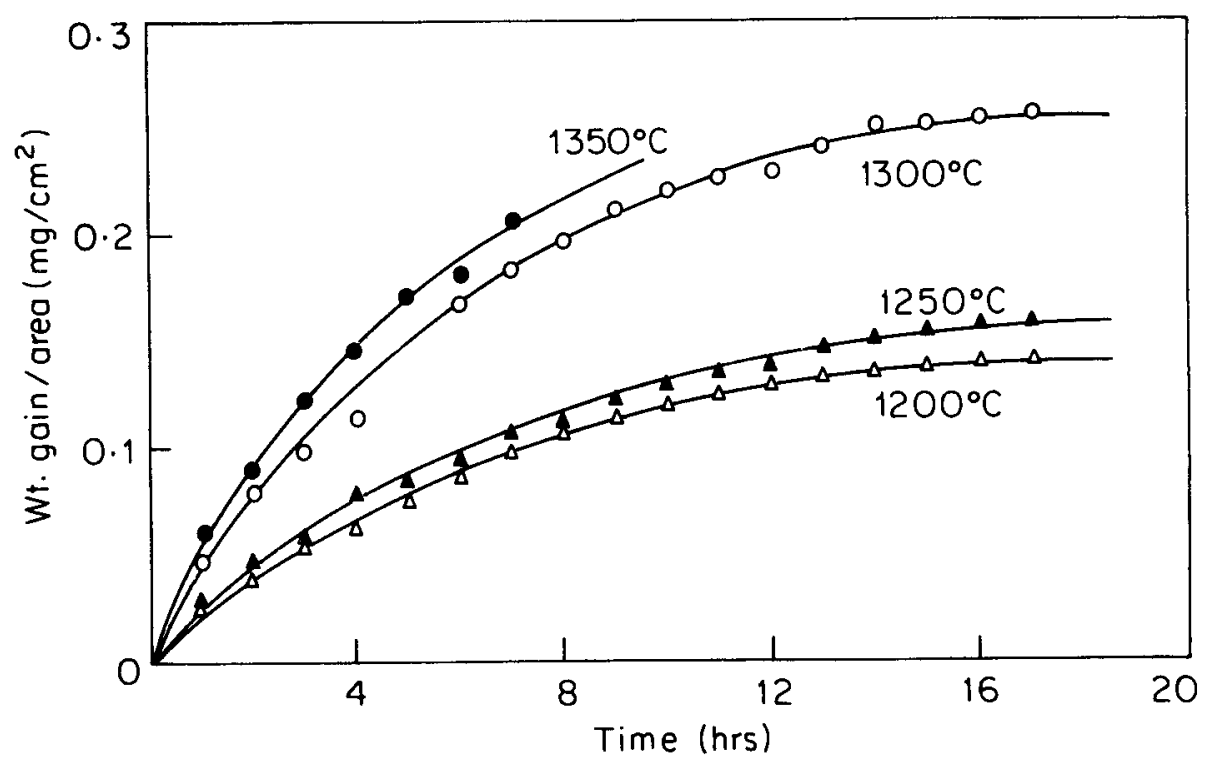

Figure 2. Oxidation weight gain vs time.

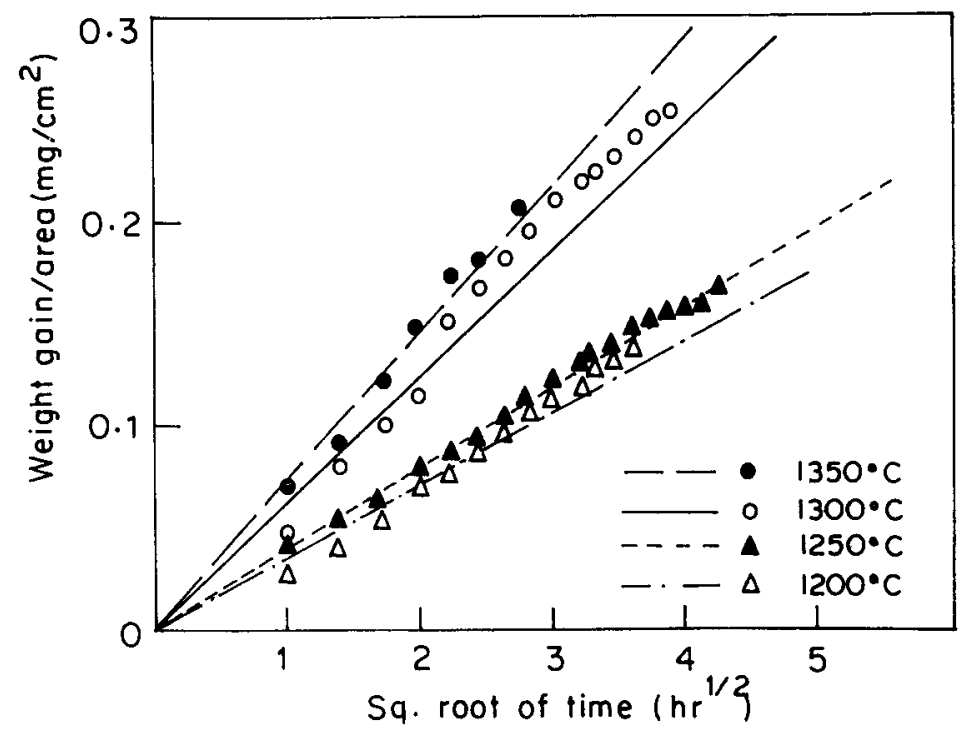

Figure 3. Oxidation weight gain vs time ${ }^{1 / 2}$.

temperature. The Arrhenius plot of $\ln k$ against $1 / T$ is shown in figure 4 . All the points, corresponding to individual test temperatures, fit to a straight line where the gradient of the line gives the value of the activation energy. The value here is $28.75 \pm$ $2 \cdot 61 \mathrm{kcal} / \mathrm{mol}$.

For silicon it is widely accepted that diatomic oxygen diffuses through the growing oxide film and controls the rate of oxidation (Deal and Grove 1965; Hopper et al 1975). Activation energy for oxidation of silicon agrees very well with the activation 


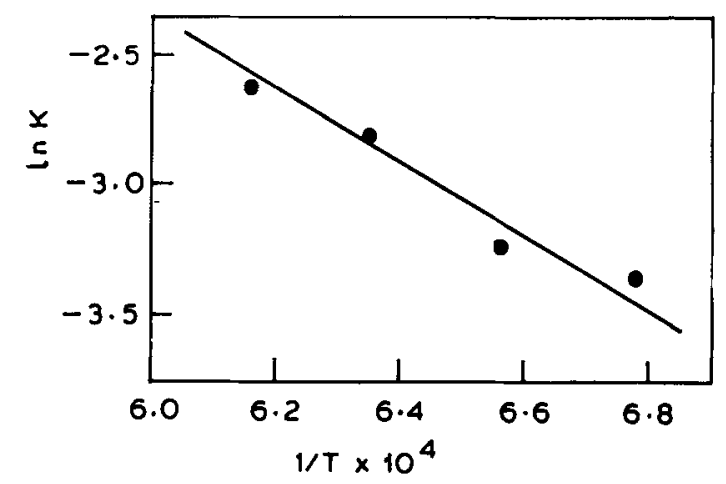

Figure 4. Plot of $\ln k$ vs $1 / T$.

energy of $113 \mathrm{~kJ} / \mathrm{mol}(26.9 \mathrm{kcal} / \mathrm{mol})$ for molecular oxygen through fused silica (Norton 1961). At low temperatures, activation energies of sintered and hot-pressed silicon carbide are found to be $134 \mathrm{~kJ} / \mathrm{mol}(31.9 \mathrm{kcal} / \mathrm{mol})$ and $155 \mathrm{~kJ} / \mathrm{mol}(36.9 \mathrm{kcal} / \mathrm{mol})$ respectively (Costello and Tressler 1981), whereas at high temperatures high values are obtained (Singhal 1976; Costello and Tressler 1981). This suggests that inward diffusion of oxygen molecules may be responsible for oxidation of silicon carbide at low temperature, similar to the process occurring in the case of oxidation of silicon. But at high temperatures high activation energy indicates that oxygen transport mechanism is most unlikely and, alternatively, it has been concluded that outward desorption of $\mathrm{CO}(\mathrm{g})$ from $\mathrm{SiC} / \mathrm{SiO}_{2}$ interface is the rate-controlling process. As our material is duplex in nature, containing original $\alpha-\mathrm{SiC}$, reaction-formed $\beta$-SiC, and an almost continuous matrix of unreacted $\mathrm{Si}$, the present result suggests that both $\mathrm{Si}$ and $\mathrm{SiC}$ oxidize and the oxidation process occurs by the inward oxygen transport mechanism. The $\mathrm{CO}$ desorption which is favoured in case of high-temperature oxidation of silicon carbide may not be rate-controlling.

\section{Conclusion}

(i) Parabolic oxidation kinetics are observed in case of oxidation of reaction-sintered silicon carbide.

(ii) The maximum weight gain is $0.2530 \mathrm{mg} / \mathrm{cm}^{2}$ at $1300^{\circ} \mathrm{C}$ for $15 \mathrm{~h}$. It indicates that the amount of scale formation is very negligible during the end-use condition of the reaction-sintered silicon carbide.

(iii) The activation energy for oxidation is found to be $28.75 \pm 2.61 \mathrm{kcal} / \mathrm{mol}$.

(iv) Inward oxygen diffusion through the oxide film is most favoured.

\section{Acknowledgements}

This work is supported by the BHEL project 'Development of sintered silicon carbide recuperator tube'. The authors thank the Director of this Institute for his interest in the work and also other sections for experimental assistance. 


\section{References}

Adamsky R F 1959 J. Phys. Chem. 63305

Costello J A and Tressler R E 1981 J. Am. Ceram. Soc. 64327

Deal B E and Grove A S 1965 J. Appl. Phys. 36770

Ervin G 1958 J. Am. Ceram. Soc. 41347

Gogotsi G A, Gogotsi Yu G, Ostrovoi D Tu and Ivaschenko O V 1989 Refractories 3084

Hinze J W, Tripp W C and Graham H C 1975 Mass transport phenomena in ceramics (eds) A R Cooper and A E Heuer (New York: Plenum Press) p. 409

Hopper M A, Clarke R A and Young L 1975 J. Electrochem. Soc. 1221216

Jorgensen P J, Wadsworth M S and Cutler I B 1959 J. Am. Ceram. Soc. 42613

Kurycheva D D and Bresker R I 1969 Ogneupory 3457

Norton F J 1961 Nature (London) 191701

Pultz W W 1967 J. Phys. Chem. 714456

Schiroky G H 1987 Adv. Ceram. Mater. 2137

Singhal S C 1976 J. Mater. Sci. 111246 